\title{
A REFORMA DO ESTADO: PERSPECTIVAS PARA O PODER JUDICIÁRIO
}

\author{
Isabella Bertoncini ${ }^{1}$
}

\section{Resumo}

O presente artigo tem como objetivo identificar a influência do modelo gerencial advindo da Reforma do Aparelho do Estado (RAP) no Brasil na Reforma do Judiciário brasileiro (Emenda Constitucional n. 45/2004). Para tanto, realizou-se um levantamento histórico dessa Reforma instituído em razão da Emenda Constitucional n. 19/1998. Utilizando-se como método a pesquisa documental e exploratória, pôde-se constatar que o modelo gerencial da RAP trouxe avanços para a administração pública brasileira, inclusive nas práticas administrativas utilizadas pelo Poder Judiciário.

Palavras-chave: Reforma do Aparelho do Estado. Reforma Judiciário. Modelo gerencial.

\section{Introdução}

Na década de 90 foi implementada a Reforma do Estado no Brasil, que buscou modernizar a gestão pública, introduzindo o modelo gerencial. As bases desta Reforma, segundo Bresser Pereira (1997), foram quatro processos básicos: delimitação das funções do Estado; a redução do grau de interferência do Estado; o aumento da governança; e a governabilidade. Por meio dela, foram estruturadas práticas de gestão com foco na eficiência, no controle de resultados, na descentralização, na qualidade e na produtividade do serviço público, e na profissionalização do servidor público.

Nesse contexto, o Poder Judiciário brasileiro encontrava-se em crise institucional, decorrente do acúmulo do número de processos, em razão da ampliação dos mecanismos de acesso à Justiça trazidos pela Constituição Federal de 1988, ocasionando a morosidade processual. Com o intuito de identificar os problemas desse Poder, o estudo "A Imagem do Judiciário junto à população Brasileira", do Centro de Pesquisas de Opinião Pública da Universidade de Brasília (UnB) apud Vieira e Pinheiro (2008), concluiu que a Justiça no Brasil não atendia às necessidades do povo brasileiro, tinha problemas de gestão e de planejamento, precisava de reformulações, era lenta, e não oferecia tratamento igualitário aos seus demandantes. 
Com vistas a criar uma Justiça mais célere e próxima do cidadão, foi editada a Emenda Constitucional n. 45/2004, conhecida como "Reforma do Judiciário". Dentre outras inovações, essa Emenda criou o Conselho Nacional de Justiça (CNJ), cuja competência é efetuar o controle da atuação administrativa e financeira do Poder Judiciário, e fazer cumprir os deveres funcionais dos magistrados.

Desta forma, o presente artigo tem como objetivo identificar a influência do modelo gerencial advindo da Reforma do Aparelho do Estado (RAP) no Brasil na Reforma do Judiciário brasileiro (Emenda Constitucional n. 45/2004). Para tanto, utilizou-se a pesquisa documental, exploratória, procurando analisar resoluções normativas e informações colhidas dos relatórios do Conselho Nacional de Justiça.

\section{A Reforma do Estado}

As reformas gerenciais ocorreram em decorrência da crise do Estado na década de 1970, e começam a ser adotadas a partir da década de 1980 por países como o Reino Unido e os Estados Unidos.

Diante do descontrole fiscal, diversos países passaram a apresentar redução nas taxas de crescimento econômico, aumento de desemprego e elevados índices de inflação. A desordem econômica evidenciava a dificuldade do Estado em continuar a administrar as crescentes expectativas em relação à política de bem-estar social, que teve relativo sucesso no pós-guerra.

Sobre esse assunto, Abrucio e Pó (2002) discorrem:

O tema da Reforma do Estado surge com força ao final da década de 70 , quando entra em crise o modelo estatal montado no pós-guerra, o qual tinha sido o agente fundamental de uma era gigantesca de prosperidade das economias capitalistas, centrais e periféricas. Neste primeiro momento, o impulso para a mudança veio da crise fiscal, iniciada com choques do petróleo e com efeitos por toda a década de 80 .

Por esta razão, as primeiras propostas de Reforma do Estado no mundo desenvolvido articulavam-se em torno da redução da dimensão e dos gastos do aparelho estatal, o que fez com que muitos identificassem nesta temática uma visão necessariamente neoliberal. As vitórias dos conservadores na Grã-Bretanha e nos E.U.A. deram o pontapé inicial neste processo, algo que incentivou ainda mais a identificação anterior. 
As ondas de "modernização" foram ativadas por fatores como a crise fiscal do Estado, a crescente competição territorial pelos investimentos privados e mão de obra qualificada, a disponibilidade de novos conhecimentos organizacionais e tecnológicos, a ascensão de valores pluralistas e neoliberais, e a crescente complexidade, dinâmica e diversidade das nossas sociedades, tornando-se o modelo burocrático alvo de críticas em razão de sua presumida ineficiência, morosidade, estilo autorreferencial e descolamento das necessidades dos cidadãos (SECCHI, 2009).

Assim, surgia um novo modelo gerencial, cujas bases, calcadas na eficiência, eram: a profissionalização da alta burocracia, transparência na administração pública, descentralização da execução dos serviços públicos, desconcentração organizacional nas atividades exclusivas do Estado, orientação para o controle dos resultados, a flexibilização da gestão, a redução dos níveis hierárquicos e o aumento da autonomia dos gerentes para a tomada de decisão (CLAD, 1998).

No contexto internacional foram identificadas duas gerações distintas de propostas de Reforma do Estado. A primeira teve início na Grã-Bretanha e nos Estados Unidos, a partir da eleição dos governos conservadores, mais especificamente a primeira-ministra inglesa Margareth Thatcher e 0 presidente americano Ronald Reagan. Os principais objetivos das reformas, naquele momento, foram o corte de custos e o aumento da eficiência do setor público, sendo adotadas políticas direcionadas ao ajuste fiscal, através da redução nos gastos públicos, reformas tributárias, liberalização econômica, desregulamentação e privatizações; essas reformas foram conduzidas com base no conceito do Estado mínimo. Já a segunda geração das reformas do Estado se desenvolveu nos anos $90 \mathrm{e}$ incorporava novas propostas, como o fortalecimento da capacidade gerencial do Estado, a melhoria da qualidade dos serviços públicos e o fortalecimento da accountability (ANDRIOLLO, 2006).

Fadul e Silva (2008) explicam que o movimento gerencialista possui vários ramos e abordagens, dentre elas a New Public Administration (a Nova Administração Pública), movimento de orientação americana, adotado e popularizado durante o governo de Ronald Reagan em 1980, e que foi disseminado através do livro de Osborne e Gaebler, Reinventando o Governo.

Osborne e Gaebler fundamentam este novo modelo em um conjunto de princípios do novo paradigma para a administração pública, destacando-se: o governo catalisador, a partir da redefinição do papel de provedor direto para promotor ("navegar, não remar"); o governo competitivo, que privilegia as vantagens da competição - a questão não é público versus privada, mas competição versus monopólio; o governo da comunidade, 
que transfere responsabilidades da burocracia para o cidadão; o governo orientado por missões e resultados, que muda o enfoque em regras e procedimentos para missões e resultados; o governo voltado para clientes, que destaca o papel preponderante de servir aos cidadãos com qualidade e enfatizando o controle social (MARINI, 2003).

A outra vertente apresentada por Fadul e Silva (2008) é a New Public Management (a Nova Gestão Pública), de orientação mais liberal, adotada pela Inglaterra durante o governo da primeira-ministra Margareth Thatcher, em 1979, e disseminada a partir das reformas administrativas realizadas no Reino Unido durante as décadas de 70 e 80 . A Nova Gestão Pública gerou quatro modelos de gerencialismo: o impulso para eficiência, o downsizing e a descentralização, a busca pela excelência, e a orientação para o público. Brulon, Ohayon e Barzelay (2001) apud Rosemberg (2012) explicam que o termo New Public Management expressa a ideia de um fluxo cumulativo de decisões políticas que levaram à mudança na governança e no gerenciamento do setor estatal, a partir do desenvolvimento de práticas de rotinas inovadoras, voltadas ao aumento do desempenho.

Por derradeiro, o Managerialism, última vertente, também de tradição inglesa, que se desdobrou em três abordagens diferentes: o modelo gerencial puro, o consumeirism, e o public service orientation.

\subsection{A reforma gerencial no Brasil}

No Brasil, a reforma gerencial, inspirada no gerencialismo britânico, também recebeu inûuência dos princípios da new public management (NPM); assim, o Plano Diretor de Reforma do Aparelho do Estado, coordenado pelo Ministério da Administração e Reforma do Estado (BRASIL, 1995), fortemente apoiado na new public management e na progressive governance, incorporou muitos elementos do paradigma neodesenvolvimentista. A implantação da NPM no Brasil procurou delinear um novo padrão de gestão pública, a denominada "administração gerencial", apoiada nos princípios da exibilidade, da ênfase em resultados, do foco no cliente e no controle social (MATIAS-PEREIRA, 2008).

Esta Reforma do Estado teve como finalidade manter as contas públicas equilibradas e, ao mesmo tempo, elevar a capacidade da ação estatal, propondo uma reconguração das estruturas estatais, e buscando a substituição do modelo burocrático de administração pública por um modelo gerencial. Por tratar-se de um modelo pós-burocrático, importou ferramentas de gestão provenientes do setor privado, bem como a aplicação da lógica de mercado dentro do setor público, focalizando o aumento 
da eciência econômica do Estado. Em consonância com as experiências internacionais que estavam em curso, dar-se-ia início a um amplo processo de revisão das formas de prestação dos serviços públicos no Brasil (MATIAS-PEREIRA, 2008).

Fadul e Souza (2005) traçam uma trajetória das principais reformas havidas no Brasil, categorizando quatro reformas paradigmáticas a partir do início do século XX. O principal marco da primeira reforma foi a criação do Departamento Administrativo do Serviço Público (DASP), durante o Estado Novo, que se caracterizou por estabelecer uma burocracia pública profissionalizada, e por institucionalizar uma gestão profissional e impessoal nos padrões weberianos. Implantada no Regime Militar de 1964, a segunda reforma, buscou desenhar um modelo de administração pública gerencial, com a publicação do Decreto Lei n. 200/67. A terceira, ocorreu com a promulgação da Constituição de 1988.

Sobre esse ponto, vale trazer o entendimento de Abrucio (2007):

A Constituição de 1988 abriu um caminho para um conjunto de grandes mudanças na administração pública brasileira. Em grandes linhas, houve três frentes de atuação na Carta Constitucional: a profissionalização da burocracia - particularmente com a universalização do concurso público -, a definição de mecanismos de controle e publicização do Poder Público e a descentralização das políticas públicas, rompendo com a tradição mais centralizadora do Estado brasileiro pós-Vargas.

Por fim, a quarta e última reforma, iniciada no Governo Collor e consolidada de forma extensiva e aprofundada nos dois governos de Fernando Henrique Cardoso, teve por base a construção do Plano Diretor da Reforma do Aparelho do Estado (PDRAE), em 1995 (FADUL; SILVA, 2008). Esse Plano, consolidado pela Emenda Constitucional n. 19, de 4 de junho de 1998, propunha a adoção de um modelo de administração pública gerencial, pautado na eficiência ${ }^{2}$, no controle de resultados, na descentralização, na qualidade, na produtividade e na profissionalização do servidor público.

O referido Plano categorizou o aparelhamento do Estado em quatro setores:

1 Núcleo estratégico: é o governo, em sentido lato, que define as leis e as políticas públicas, e cobra o seu cumprimento. É onde as decisões estratégicas são tomadas. É composto pelos Poderes Legislativo e Judiciário, Ministério Público, Presidência da República (Poder Executivo), ministros, assessores diretos, responsáveis pelo planejamento e pelas políticas públicas; 
2 Atividades exclusivas: setor em que são prestados os serviços que só o Estado pode realizar. É onde reside o poder extroverso do Estado, constituído pelo poder de regulamentar, fiscalizar, fomentar. Tem-se como exemplo a cobrança de impostos, a polícia, o controle do meio ambiente;

3 Serviços não-exclusivos: setor em que o Estado atua simultaneamente com outras organizações públicas não-estatais e privadas, atividades que envolvem os direitos humanos fundamentais, tais como educação e saúde (universidades, hospitais ${ }^{3}$, museus);

4 Produção de bens e serviços para o mercado: área de atuação das empresas. Atividades econômicas voltadas ao lucro que ainda permanecem no Aparelho do Estado (infraestrutura) (BRESSER PEREIRA, 1997, p. 41).

À época da implantação da reforma gerencial do Estado, Bresser Pereira (1999), mentor do PDRAE, traçou um diagnóstico da administração pública brasileira, identificando três dimensões de problemas: (1) dimensão institucional-legal, concernente a obstáculos de ordem legal, que impediam o alcance de maior eficiência do aparelho do Estado; (2) dimensão cultural, contrastando os valores à época existentes (patrimonialistas e burocráticos) com os novos valores (gerenciais e modernos); (3) dimensão gerencial, que consistia na aplicabilidade das novas práticas administrativas.

Com o intuito de dirimir tais entraves, foram estruturados os seguintes processos básicos da Reforma do Estado, in verbis:

(a) delimitação das funções do Estado, reduzindo seu tamanho em termos, principalmente, de pessoal, através dos programas de privatização, terceirização e "publicização"4 (este último processo implicando na transferência para o setor público não-estatal dos serviços sociais e científicos que hoje o Estado presta);

(b) a redução do grau de interferência do Estado ao efetivamente necessário através de programas de desregulação que aumentem o recurso aos mecanismos de controle via mercado, transformando o Estado em um promotor da capacidade de competição do país a nível internacional, ao invés de promotor na economia nacional contra competição internacional;

(c) o aumento da governança do Estado, ou seja, da sua capacidade de tornar efetivas as decisões do governo, através do ajuste fiscal, que devolve autonomia financeira ao Estado, da reforma administrativa rumo a uma administração pública gerencial (ao invés de burocrática), e a separação, dentro do Estado, ao nível das atividades 
exclusivas do Estado, entre a formulação de políticas públicas e sua execução; e, finalmente,

(d) o da governabilidade, ou seja, do poder do governo, graças à existência de instituições políticas que garantam uma melhor intermediação de interesses e tornem mais legítimos e democráticos os governos, aperfeiçoando a democracia representativa e abrindo espaço para o controle social ou democracia direta ${ }^{5}$. (BRESSER PEREIRA, 1997)

Abrucio (2007) ressalta os principais avanços obtidos pela chamada reforma Bresser. A primeira mudança foi a continuação e o aperfeiçoamento da civil service reform, com grande reorganização administrativa do governo federal, especialmente no que concerne à melhoria substancial das informações da administração pública - antes desorganizadas ou inexistentes - e ao fortalecimento das carreiras de Estado. Um número significativo de concursos foi realizado e a capacitação, feita pela revitalizada Escola Nacional de Administração (Enap); em síntese, "“...] o ideal meritocrático contido no chamado modelo weberiano não foi abandonado pelo MARE; ao contrário, foi aperfeiçoado". Já a segunda se refere ao aspecto legal, em especial na reforma constitucional, com as Emendas n. 19 e 20, sendo introduzidas medidas referentes ao teto para o gasto com funcionalismo, alterações no caráter rígido no Regime Jurídico Único, e introdução do princípio da eficiência entre os pilares do direito administrativo. Tais mudanças constituíram peças essenciais na criação de uma ordem jurídica que estabeleceu parâmetros de restrição orçamentária e de otimização das políticas.

Acrescenta que o então ministro Bresser também foi responsável por um movimento de disseminação das novas formas de gestão, orientadas pela melhoria do desempenho do setor público. Ressalta que, neste aspecto, a existência do plano diretor como diretriz geral de mudanças teve um papel estratégico, sendo essencial para dar um sentido de comprometimento às ações, ultrapassando a manifestação normalmente fragmentadora das boas iniciativas de gestão. Assim, a partir de Bresser, concebeu-se a ideia de uma administração voltada para resultados, ou "modelo gerencial", como era chamado à época.

Contudo, Fadul e Silva (2008, p. 15), ao analisarem a implantação do gerencialismo trazido pela Reforma do Estado no Brasil, afirmam que

[...] a nova administração pública, do modo como se instalou no Brasil, conseguiu alguns êxitos no campo instrumental, objetivo, mas no campo substantivo, social, além do seu impacto ser limitado, não conseguiu dar conta de muitas questões, além de não ter conse- 
guido superar, de forma mais contundente, as heranças provindas tanto do patrimonialismo, como do modelo burocrático de gestão. Para o gerencialismo se estabelecer nas organizações públicas é preciso superar barreiras políticas, ideológicas e corporativas, existentes no âmbito do funcionalismo público e nos atuais desenhos organizacionais e institucionais. Consideradas as suas limitações e a trajetória histórica e política inconclusa que a reforma ainda mantém, fica, por fim, a reflexão sobre o custo social de manutenção no equilíbrio fiscal (FADUL; SILVA, 2008, p.15, sem grifo no original).

Por outro lado, ao avaliar a atuação da gestão pública brasileira nos governos Fernando Henrique Cardoso e Lula, Abrucio (2011) pontua as linhas que mereceram destaque: gestão por resultados, governança federativa e mecanismos de controle público. No primeiro caso, observou que houve a continuidade, nos dois governos, com também a expansão das metas por resultados para alguns governos estaduais. A governança federativa, por sua vez, caminhou mais para a articulação governamental, em especial nas áreas de saúde e educação, e para a redescentralização na área tributária. No que se refere aos mecanismos de controle, ainda que frágeis, avançaram, especialmente por meio de instituições como a Controladoria Geral da União, os Tribunais de Contas e o Ministério Público.

O balanço geral que esse autor faz é que os dois governos trouxeram melhoria significativa para a administração pública brasileira, apesar dos déficits ainda existentes. Afirma, ainda, que foi constatado o aperfeiçoamento contínuo no processo de profissionalização meritocrática das carreiras do Estado, muito embora "[...] persista uma relação precária dos partidos e do Legislativo com o tema gestão pública" (ABRUCIO, 2011, p. 119).

\section{A reforma do Judiciário}

Após doze anos de tramitação no Congresso Nacional, resultado de um longo processo de amadurecimento, impulsionado pela necessidade do Judiciário em se modernizar, para ampliar o acesso das pessoas à prestação jurisdicional do Estado e garantir que os serviços prestados à sociedade sejam de melhor qualidade, foi editada a Emenda Constitucional n. 45, de 8 de dezembro de 2004, conhecida como "Reforma do Judiciário", promulgada em meio a críticas ao funcionamento do Poder Judiciário e à pressão da sociedade por uma Justiça mais célere e próxima do cidadão. 
A necessidade de reforma deu-se em razão da crise do sistema de justiça brasileiro. Sadek (2004) aponta que, à época anterior à referida Emenda, já havia um descontentamento geral em relação ao anacronismo, à inoperância e à desigualdade no acesso aos serviços judiciais, como também havia críticas ao insatisfatório desempenho das instituições encarregadas de distribuir justiça, incapazes de responder à crescente demanda judicial e refratária a qualquer modificação.

Renault (2005) identifica os principais problemas que explicam o mau funcionamento do sistema judicial brasileiro: lentidão na tramitação dos processos judiciais, pouca transparência, obsolescência administrativa, dificuldade de acesso, complexidade estrutural, concentração de litigiosidade, e desarticulação institucional.

Ao analisar tais dificuldades, Sena (2012) afirma que a lentidão na tramitação dos processos judiciais no país decorre da existência de um complexo sistema jurídico-legal, que prioriza os procedimentos, em detrimento da satisfação da pretensão judicial. Dessa forma, os processos perduram anos, muitas vezes em razão da utilização, pelos operadores do direito, de mecanismos protelatórios, que culminam por reduzir as expectativas dos demandantes, gerando, assim, um alto custo social e financeiro.

No que tange à obsolescência administrativa, esta ocorre em razão da dificuldade histórica do Poder Judiciário em se modernizar, fazendo adequada utilização dos recursos tecnológicos disponíveis no mercado para oferecer um serviço (público) de qualidade à população. A dificuldade de acesso se dá em razão do próprio custo desse serviço, que impossibilita o acesso da população mais carente à justiça do país, assim como em razão da localização - apesar de haver vários tribunais no Brasil, estes se encontram localizados em cidades de médio e grande porte, havendo considerável número de municípios sem estrutura judicial, inclusive itinerante.

No que diz respeito à complexidade estrutural, é sabido que o sistema judiciário brasileiro é composto por diversos órgãos e estruturas que dificultam sua compreensão. Tal complexidade decorre da própria Constituição Federal, que disciplina a organização do Poder Judiciário, como bem coloca Renault (2005):

Há, na verdade, vários poderes judiciários. Temos a Justiça Federal, a justiça comum dos estados da Federação, as justiças especializadas (militar, trabalhista e eleitoral, a primeira e a segunda instâncias, os tribunais superiores, os juizados especiais etc.). Em 
suma, temos 91 tribunais com grande nível de autonomia administrativa e praticamente nenhuma interligação entre eles. (RENAULT, 2005, p. 128).

A concentração de litigiosidade resulta na excessiva convergência de processos que respondem a interesses das grandes corporações empresariais e financeiras, da União, estados e municípios, congestionando grande parte dos tribunais do país. É o que Sadek (2004) chama de 'demandas de mais' e 'demandas de menos', ou seja, poucos procurando muito, e muitos procurando pouco ou não procurando a justiça.

Por fim, a desarticulação institucional, que decorre da ausência de envolvimento dos agentes públicos no tratamento das questões concernentes ao sistema judiciário. Os problemas são considerados questões internas, de interesse dos magistrados e das associações de classe.

Sadek (2004) analisa a atuação do Poder Judiciário sob dois enfoques:

a) como Poder de Estado, que garante aos magistrados a capacidade de agirem politicamente, quando permite o questionamento e a paralisação de políticas e de atos administrativos aprovados pelos demais Poderes, possibilitando a determinação de medidas de forma independente da vontade expressa do Executivo e da maioria parlamentar; e,

b) como agência pública prestadora de serviços, tratando-se de um serviço público encarregado da prestação da tutela jurisdicional, arbitrando conflitos e garantindo direitos.

Sobre o primeiro aspecto, oportuno registrar que a Constituição de 1988 ampliou os direitos individuais, estabelecendo que o núcleo do próprio Estado brasileiro é a proteção dos direitos fundamentais - e fundamentais são os direitos individuais, de primeira geração, provenientes de reivindicações de não intervenção do Estado, os de segunda geração, referentes a prestações positivas do Estado, e de terceira geração os direitos difusos e coletivos. Assim, quanto mais direitos, maior a demanda: se todo direito merece proteção judicial, maiores são as demandas judiciais, incluindo a avaliação da regularidade do processo legislativo e definição de políticas públicas.

Mais do que judicializar ${ }^{6}$ a política, a Constituição cidadã fez com que a discussão política encontrasse no Judiciário uma arena mais propícia a se desenvolver ${ }^{7}$ (RODOVALHO, 2012). Contudo, tal alargamento de direitos gerou uma prestação falha de serviços jurisdicionais, uma vez que a estrutura do Judiciário permaneceu a mesma, aumentando o volume de 
trabalho dos serventuários da Justiça; ademais, ainda persistem as deficiências decorrentes da legislação processual, que é extremamente formalista e excessiva em recursos.

Dessarte, o que se pode observar é que há uma carência de sintonia das políticas públicas com efeito no funcionamento do judiciário, tendo em vista que se alargam os direitos, mas não se equipa o Judiciário com pessoal, tecnologia e recursos para atender esses direitos. Pode-se citar como exemplo o acesso à Justiça, não há carência de normas que garantam os direitos, mas meios para que esses direitos sejam defendidos em juízo. Com a Carta Magna foi criada a Defensoria Pública ${ }^{8}$, todavia, em levantamento recente (2013) produzido pela Associação Nacional dos Defensores Públicos (ANADEP) em parceria com o Instituto de Pesquisa Econômica Aplicada (Ipea), foi comprovada a falta de defensores públicos em $72 \%$ das comarcas, ou seja, os dados mostram que a defensoria só está presente em 754 das 2.680 comarcas do país.

O mapa resultante dessa pesquisa permite apontar problemas e características, como casos de defensores que, além da própria lotação, atendem outras comarcas, de modo itinerante ou em extensão. Outro aspecto importante revelado no estudo é a discrepância dos investimentos no sistema de Justiça: há estados que contam com 11.835 magistrados, 9.963 membros do Ministério Público e 5.054 defensores públicos; ou seja, na grande maioria das comarcas brasileiras, a população tem só juiz e acusação, sem o defensor, que, em tese, deveria cuidar dos interesses jurídicos da parte da população que não pode contratar um advogado particular ${ }^{9}$.

Nesse sentido, Paula (2006) assevera:

A deficiência no sistema de provocação decorre do pouco caso na estruturação das defensorias públicas no País, que, embora não surjam da responsabilidade do Poder Judiciário, vão influir drasticamente na manutenção de um sistema de privilégio, determinando a inacessibilidade do Judiciário ao economicamente hipossuficiente e, por consequência, afetando o exercício da cidadania.

No que concerne à segunda dimensão - agência pública prestadora de serviços -, verifica-se uma distinção entre acesso ao Judiciário (demanda) e processamento da demanda. Neste último os sintomas da crise do Judiciário são mais evidentes, pois "diz respeito a uma estrutura pesada, sem agilidade, incapaz de fornecer soluções em tempo razoável, previsíveis e a custos acessíveis para todos" (SADEK, 2004, p. 88). 
Vieira e Pinheiro (2008) apontam que as causas para a crise do Judiciário podem ser vistas sob os aspectos processual e estrutural. As primeiras, apontadas com maior frequência por Costa, Martinewski, Vieira (2006) e Paula (2006), decorrem do número excessivo de recursos previstos em lei, do crescimento do número de processos novos a cada ano, do excesso de formalismo cartorial, das formalidades protelatórias nas audiências, e da improbidade das leis (abundância de leis, inadequação aos fatos que pretendem reger e má elaboração). As intituladas como de ordem estrutural, segundo esses autores, são:

[...] o difícil acesso ao Judiciário por setores da população; o fato de o Judiciário não ser mais órgão de exceção, a ser consultado somente quando todas as demais instâncias para a composição dos conflitos não funcionarem; número insuficiente de magistrados e servidores; ingresso de servidores não vocacionados e desmotivados; falta de instalações físicas adequadas; a pouca informatização dos cartórios e varas judiciais; a falta de planejamento; a incapacidade de gestão; a deficiência no controle administrativo; e a falta de estruturação das demais instituições que integram o Sistema de Justiça, em especial a Polícia e a Defensoria Pública.[VIEIRA E PINHEIRO, 2008 apud Costa, Martinewski, Vieira (2006) e Paula (2006)]

Diante do contexto em que se encontrava o Brasil - resultado de décadas de uma gestão ineficiente, lentidão na prestação jurisdicional, implicando em um serviço caro, pouco democrático e desprovido de transparência, a Reforma do Judiciário foi colocada na agenda política no início do mandato do Presidente Luís Inácio Lula da Silva, com o intento de ampliar o acesso das pessoas à prestação jurisdicional do Estado e garantir que os serviços prestados fossem de melhor qualidade (RENAULT, 2005).

Rodovalho (2012) elenca como motivos para reformar o Judiciário: reduzir a morosidade da justiça; resolver problemas da judicialização da política e abrir o Judiciário para os mais pobres; diminuir o custo, não só com a manutenção dos serviços (incluindo pessoal e patrimônio), como também o custo social, que representa o desempenho do Judiciário.

Dificuldades de todas as ordens (nem sempre devidas apenas ao Judiciário, senão a todo o Estado), caracterizaram a chamada "crise de legitimidade do Judiciário". Assim, a Reforma trouxe como principais inovações:

a) planejamento e controle do Poder Judiciário, com a criação de órgãos de controle externo ao Judiciário e ao Ministério Público - Conse- 
Iho Nacional de Justiça e Conselho Nacional do Ministério Público (arts. 103-B e 130-A, da Constituição Federal);

b) eficiência e celeridade no Judiciário, com a instituição da súmula vinculante ${ }^{10} \mathrm{e}$ da repercussão geral como requisito necessário ao recurso extraordinário ${ }^{11}$, e com a criação de um plano de metas pelo CNJ, com o fim de atingir os resultados almejados pela instituição;

c) autonomia e independência dos magistrados, com a afirmação dos princípios constitucionais correlatos, trazendo autonomia financeira ao Poder Judiciário, estabelecendo critérios unificados para o ingresso na magistratura e no Ministério Público, e instituindo a quarentena para o exercício da advocacia; e,

d) funções essenciais e acesso à justiça, por meio da concessão de autonomia às defensorias públicas.

Dentre essas medidas, destaca-se a criação do CNJ como de fundamental importância para que o Poder Judiciário fosse mais transparente, propiciando algum controle da sociedade.

Consoante Sena (2012, p.8):

[...] as antigas práticas administrativas do Poder Judiciário começaram a ser fiscalizadas por esse novo órgão, o qual impôs uma série de metas aos tribunais brasileiros, visando, sobretudo, tornar a justiça brasileira mais célere e transparente. Além disso, novos mecanismos de gestão foram implantados, instituições foram fortalecidas, com o escopo de ampliar o acesso à justiça no país, além de tornar este serviço público essencial mais ágil, eficaz e menos oneroso para a sociedade brasileira.

\section{Conselho Nacional de Justiça - CNJ}

O CNJ foi criado pela Emenda Constitucional n. 45, de 31 de dezembro de 2004 (Reforma do Judiciário), e instalado a 14 de junho do ano seguinte, para exercer a função de controle externo do Judiciário. Compõe a cúpula do Sistema de Justiça, estando abaixo do Supremo Tribunal Federal.

De composição heterogênea, é integrado também por não magistrados. Dos quinze membros, nove são magistrados oriundos de diversas instâncias e órgãos do Poder Judiciário, dois são membros do Ministério Público, dois advogados e dois cidadãos. Seus membros são chamados Conselheiros. O CNJ é presidido pelo Ministro-Presidente do Supremo Tribunal Federal, que vota em caso de empate. 
Houve grandes resistências corporativas quando da criação desse órgão. AAssociação dos Magistrados do Brasil (AMB) impetrou uma ação direta de inconstitucionalidade no Supremo Tribunal Federal (ADI n. 3.367/ 2004), afirmando que a instituição do CNJ, formado por representantes de outros poderes, ofenderia o princípio da separação e da independência dos poderes, além de atentar contra o pacto federativo - a ação foi julgada oportunamente improcedente.

Suas principais atribuições são: a) definir o planejamento estratégico e a gestão administrativa dos tribunais; b) controlar disciplinar e correicionalmente as atividades dos magistrados; e, c) controlar a atuação administrativa e financeira do Poder Judiciário brasileiro, à exceção do Supremo Tribunal Federal (STF), e supervisionar o desempenho funcional dos magistrados.

Dentre suas diretrizes, merecem destaque: a) planejamento estratégico, controle e proposição de políticas judiciárias; b) modernização tecnológica do Judiciário; c) ampliação do acesso à justiça, da pacificação e da responsabilidade social; d) garantia de efetivo respeito às liberdades públicas e às execuções penais. Para operacionalizar tais diretrizes, o CNJ implementou um plano de metas, as quais definem indicadores de eficiência, de produtividade e de qualidade para o Poder Judiciário, a fim de tornar o serviço público judiciário mais efetivo.

Sena, Silva e Luquini (2012) realizaram pesquisa com o objetivo de verificar como o panorama da Reforma do Estado afetou o Poder Judiciário brasileiro. Para tanto, foram analisadas vinte e nove metas propostas pelo CNJ, de 2009 a 2011, identificando como categorias: a celeridade processual, a gestão do Poder Judiciário, a capacitação dos servidores, a informatização e a transparência, e a responsabilidade social.

Foi constatado que sete metas tinham por fim dar efetividade ao princípio da celeridade processual ${ }^{3}$, visando desafogar os tribunais e tornar a justiça mais rápida. Por outro lado, em pesquisa publicada pelo Instituto de Pesquisa Econômica Aplicada (Ipea) em 31 de maio de 2011, no âmbito do denominado Sistema de Indicadores de Percepção Social (SISPS), que retratou os Sistemas de Justiça no Brasil na avaliação da população, o quesito rapidez da justiça teve a pior avaliação.

Já a segunda categoria - gestão do Poder Judiciário - englobou nove orientações, com a finalidade de desenvolver novos métodos de gestão administrativa no Poder Judiciário, abrangendo desde a elaboração do planejamento estratégico até a facilitação do acesso dos magistrados aos sistemas oficiais de informação, com o intento de agilizar o procedimento de coleta de informações sigilosas. 
No que tange ao planejamento estratégico, foi disciplinado pela Resolução n. 70, de 18 de março de 2009, fixando objetivos e diretrizes, determinando aos tribunais que o elaborasse, tomando como base os temas da eficiência operacional, do acesso à justiça, da responsabilidade social, do alinhamento e da integração, da atuação institucional, da gestão de pessoas e de infraestrutura (Figura 1).

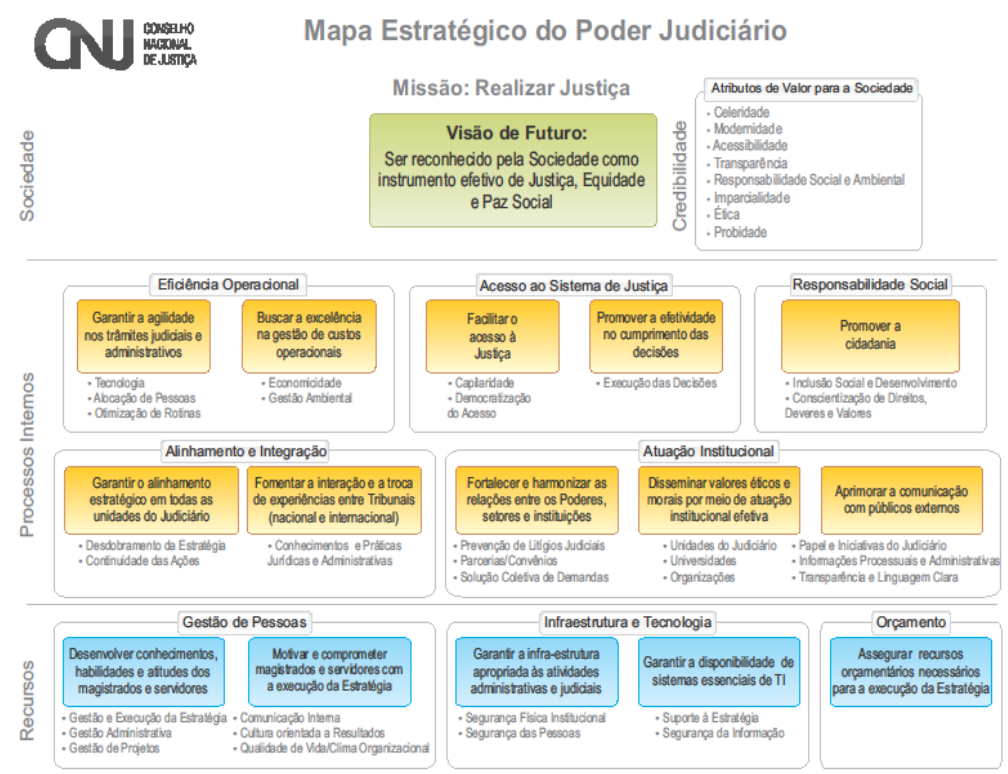

Figura 1 - Mapa estratégico do Poder Judiciário

Fonte: CNJ (2011)

Segundo documento do CNJ intitulado "Estratégia do Poder Judiciário", o mapa estratégico tem como finalidade definir o caminho (estratégia) para se alcançar a Visão de Futuro (principal objetivo de longo prazo) e realizar a Missão (razão de ser), o que é obtido mediante a articulação de objetivos estratégicos dispostos em perspectivas (sociedade, processos internos e recursos), e ligados por relações de causa e efeito que propiciam a identificação de ações necessárias ao alcance de cada objetivo. Além disso, foram elaborados indicadores para mensurar o alcance da estratégia e, por conseguinte, as metas e os projetos prioritários com vistas a obter um melhor desempenho para a atuação do Judiciário (CNJ, 2009). 
Sobre o assunto, vale trazer o comentário de Lima e Cruz (2011) sobre Resolução n. 70/2009, verbis:

Assim, após a construção de um mapa estratégico, importante para a identificação da trajetória a ser seguida pelo Judiciário brasileiro, foram estabelecidas 10 metas a serem alcançadas pelo Judiciário em 2009. E, então, a partir deste direcionamento, os órgãos do poder judiciário começaram a construir os seus planejamentos estratégicos utilizando a metodologia Balanced Scorecard (BSC), previamente definida pelo Conselho para a formulação e acompanhamento do planejamento estratégico. Tal metodologia preconiza o uso de indicadores de desempenho e favorece a gestão por resultados.

A terceira categoria foi a capacitação de servidores e magistrados (meta 6 de 2009 e meta 8 de 2010) em gestão estratégica, preparando os primeiros em administração judiciária e os segundos em gestão de pessoas e processos de trabalho.

A quarta categoria, dividida em duas vertentes (informatização e transparência) que se complementam, facilitando sobremaneira o acesso dos operadores do Direito às informações judiciais, além de proporcionar à sociedade acesso a dados que antes eram restritos a servidores e magistrados. Neste quesito, foi constatado que nove metas propostas têm por objetivo informatizar os diversos procedimentos inerentes à atividade jurisdicional, propiciando transparência à prestação jurisdicional, haja vista a disponibilização mensal da produtividade dos magistrados nos portais dos respectivos tribunais, incluindo a quantidade de julgamentos com ou sem resolução do mérito, e homologatórios de acordos, subdivididos por competência.

Por fim, a responsabilidade social (metas 4 e 7 de 2011), com o escopo de esclarecer a população sobre as funções, as atividades e os órgãos do Poder Judiciário.

No que se refere à produtividade, registre-se a implantação, pelo $\mathrm{CNJ}$, do programa Justiça em Números ${ }^{13}$, que acompanha e divulga a produtividade de todos os magistrados brasileiros. Outra ferramenta implantada pelo CNJ foi o Banco de Boas Práticas de Gestão do Poder Judiciário, que apresenta técnicas de gestão que tornam a administração eficiente e eficaz, e promove a divulgação e o compartilhamento de projetos e ações desenvolvidas pelos tribunais.

Destarte, é possível perceber o grande enfoque dado às metas gestão do Poder Judiciário e informatização/transparência - dezoito das vinte 
nove metas estabelecidas de 2009 a 2011 (62\%), utilizam indicadores de eficácia e eficiência, demonstrando o viés gerencial desta Reforma e buscando oferecer à sociedade um serviço público mais transparente, moderno e menos oneroso. A celeridade processual também merece destaque $(24,14 \%)$, demonstrando o interesse em atender a demanda da sociedade brasileira, no sentido de propiciar a razoável duração dos processos e o acesso à Justiça.

Freire e Rover (2012) avaliaram as principais inovações do Sistema de Justiça a partir da leitura e da análise dos relatórios anuais das atividades do CNJ, confrontadas com as pesquisas de percepção da população sobre o Judiciário e com as pesquisas de juristas que serviram de referência para a Reforma do Judiciário ${ }^{14}$, tendo observado maior transparência, ampliação dos canais de informação, investimentos maciços em informatização e eficiência, estabelecimento de planejamento e de metas, e avaliação dos processos de gestão, realidade esta que inexistia no sistema judicial antes da Reforma.

Nessa pesquisa foram estudadas as resoluções do $\mathrm{CNJ}$, desde sua criação até dezembro de 2011, sendo identificadas 34 resoluções que versam, direta ou indiretamente, sobre o uso das novas tecnologias, representando um percentual de quase $30 \%$ das 125 resoluções publicadas. Para melhor análise, essas novas tecnologias foram classificadas em três categorias: transparência e informação (accountability); serviços e processo eletrônico; e gestão.

Os temas mais frequentes tratam da transparência do Poder Judiciário, garantindo informações sobre estatísticas, banco de soluções, endereços eletrônicos, gastos e orçamentos (detalhados), plano estratégico, plantões dos juízes, comunicação social, prestação de contas (inserção do Portal Transparência em todos os tribunais), ouvidorias, entre outros. No entanto, a referida análise não parte de uma classificação estanque; algumas resoluções podem ser classificadas em mais de um assunto, principalmente no que concerne à transparência, por exemplo. A maioria das resoluções ligadas à gestão torna transparente a administração do Judiciário, compreendendo uma ação de accountability (MORAES; FREIRE, 2011).

No que tange ao estabelecimento de planejamento e de metas, e à avaliação dos processos de gestão, a própria inserção do art. 103-B, §4 incisos VI e VII, na Constituição Federal, por meio da Emenda Constitucional n. 45/2004 (incluindo o CNJ na cúpula do Sistema de Justiça, com foco no controle das atividades administrativas, de planejamento e elabo- 
ração de relatórios estatísticos e de comunicação), é indicativa da necessidade de políticas públicas abrangendo diagnóstico, planejamento, implementação e avaliação.

Em que pese que tais medidas ainda não impactaram na imagem da justiça junto à população, de acordo com a pesquisa divulgada pelo Ipea2011, observa-se que uma série de práticas ainda em curso apontam para uma nova estrutura e atuação do Judiciário, carecendo, ainda, de maior apropriação da sociedade, para que o que foi estabelecido esteja em sintonia com as necessidades sociais.

Assim, o Conselho Nacional de Justiça, como órgão formulador de políticas públicas, contribuiu sobremaneira para a construção de uma cultura de planejamento em nível nacional, uma vez que inovou ao iniciar um processo de virtualização, promovedor de aproximação do Sistema de Justiça com a sociedade, seja por sua transparência (accountability), seja pelos serviços inovadores (processo eletrônico) ou por uma gestão mais democrática. Ao efetuar a análise da Reforma do Judiciário, verificase o início de uma mudança de estrutura e organização no sistema judiciário brasileiro, mas que ainda não repercutiu de forma efetiva na percepção da população brasileira.

Na avaliação de Rodovalho (2012), a grande mudança da EC n. 45/ 2004 foi a criação do CNJ, contudo, o conjunto de medidas adotadas não reduziu o acúmulo, nem proporcionou o aumento do número juízes; não houve impacto sobre a entrada de novas demandas. Ao discorrer sobre a atuação do Judiciário, a autora afirma que a criação do CNJ teve dois efeitos: I) a estipulação de metas de atuação, com a avaliação do número de decisões, estabelecendo uma tensão de realizar, ao mesmo tempo, os papéis do Judiciário integrante da arena de discussão de direitos (metas constitucionais), ou, como parte da Administração Pública, alicerçada nos propósitos de eficiência e rapidez; ou seja, a grande dificuldade de se constituir um Judiciário ao mesmo tempo justo e eficiente ${ }^{15}$; ii) proximidade de atuação do $\mathrm{CNJ}$ ao de controle externo; nesse sentido, é notória a importância da publicidade, divulgando os dados relativos ao Poder Judiciário, e da transparência promovida por esse órgão, propiciando a viabilização da accountability também nos Tribunais.

Assim, ao criar o CNJ, acaba por se estabelecer um novo critério de duração do processo, instaurando a ideia de que a eficiência da prestação jurisdicional está mais atrelada à duração do processo do que à de justiça na decisão. 
Por fim, verifica-se o processo incremental nas ações do Poder Judiciário, tanto na Reforma do Judiciário ${ }^{16}$ quanto na atuação do CNJ. É o que constata Motta (2010), verbis:

Por se inserirem em um sistema social e econômico maior, as organizações judiciárias são tanto entidades autônomas e independentes quanto partes de redes complexas em constante alteração. Apesar de rupturas bruscas não ocorrerem com frequência, há um processo cotidiano e incremental de mudanças afetando objetivos e metas já programados: ações e consensos são provisórios e sujeitos ao dinamismo organizacional. Por exemplo, novas demandas trazidas ao Poder Judiciário refletem situações problemáticas variadas, experimentadas por uma diversidade de grupos populacionais. Mesmo problemas de grande visibilidade, e de solução aparentemente fácil, são de implementação difícil, em razão de as diferenças sociais e as formas de agregação de interesses influenciarem as decisões sobre distribuição de recursos. Ademais, a maior consciência sobre os direitos de cidadania e de acesso leva não só ao crescimento da demanda como também à maior expectativa sobre a qualidade dos serviços (MOTTA, 2010).

\section{Conclusões}

A Reforma do Estado no Brasil instituiu a gestão por resultados, a governança federativa, bem como mecanismos de controle público. Esse modelo gerencialista trouxe avanços, como melhoria nas informações da Administração Pública, fortalecimento das carreiras do Estado, fixação do teto para gastos com funcionalismo, alteração no Regime Jurídico Único, e a introdução do princípio da eficiência (Emendas n. 19 e 20), contudo, no campo substantivo e social, teve um impacto limitado.

A Constituição de 1988 ampliou os direitos individuais, aumentando a demanda judicial fundamentada nesses direitos e gerando uma prestação falha de serviços judiciais, já que a estrutura do Judiciário permaneceu a mesma. Assim, cresceu o volume de trabalho dos serventuários da Justiça, agravando os sintomas já existentes no Poder Judiciário da então chamada "crise do Judiciário", como o da morosidade processual; ademais, acresce-se a esse problema as deficiências da legislação processual, extremamente formalista e excessiva em recursos.

A edição da Emenda Constitucional n. 45/2004 (Reforma do Judiciário) buscou amenizar este quadro; contudo, na visão de Rodovalho (2012), as medidas adotadas não reduziram o acúmulo de processos, nem aumentaram o número de juízes, tampouco provocaram a diminuição da 
entrada de novas demandas. Como pontos positivos, essa autora destaca a inclusão dos princípios da celeridade processual (garantia de que o processo judicial terá duração razoável) e da proporcionalidade de juízes (os cargos serão distribuídos pelo país levando em conta a demanda processual e a população das localidades) à Constituição Federal, facilitando, assim, a adoção de critérios objetivos de planejamento. Também criou o Conselho Nacional de Justiça, órgão responsável pelo controle da atuação administrativa e financeira do Poder Judiciário.

Dentre as iniciativas desse órgão, merece destaque a Resolução CNJ n. 70/2009, que disciplinou o planejamento e a gestão estratégica no âmbito do Poder Judiciário, estabelecendo objetivos e diretrizes, e determinando aos tribunais que elaborassem seus planejamentos estratégicos, alinhados com o do Judiciário Nacional, inovando ao dar início à construção de uma cultura de planejamento em nível nacional. Todavia, tal mudança ainda não repercutiu de forma efetiva na percepção da população brasileira.

Assim, é possível concluir que práticas do modelo gerencial, trazidas pela Reforma do Aparelho do Estado, influenciaram as rotinas do Judiciário, por trazendo resultados positivos, entre eles: maior transparência, ampliação dos canais de informação, implementação de planejamento estratégico e avaliação dos processos de gestão.

Há de se registrar que as iniciativas do $\mathrm{CNJ}$ caminham para a realização de um diagnóstico até então inexistente no Poder Judiciário, com o intento de que se efetive uma mensuração e um planejamento mais críticos. Para que isto ocorra, é preciso que se instaure uma mudança de cultura, de práticas, de procedimentos, o que, via de regra, não se dá de maneira imediata.

\section{Referências}

ABRUCIO, Fernando Luiz; LOUREIRO, Maria Rita Garcia. Política e Reformas fiscais no Brasil recente. Revista de Economia Política, São Paulo, v.24, n.1, p.50-72, 2004.

ABRUCIO, Fernando Luiz. Trajetória recente da gestão pública brasileira: um balanço crítico e a renovação da agenda de reformas. Revista Brasileira de Administração Pública, v. 1, p. 77-87, 2007.

ABRUCIO, Fernando Luiz. Três agendas, seus resultados e um desafio: balanço recente da administração pública federal brasileira. Desigualdade \& diversidade - Dossiê Especial (PUCRJ), dez., p.119-142, 2011. 
ABRUCIO, Fernando Luiz; PÓ, Marcos Vinicius. Trajetórias da literatura sobre Reforma do Estado (1995-2002): transformações e desafios para a pesquisa em administração pública. Brasília: ENAP - Escola Nacional de Administração Pública, 2002 (Relatório de Pesquisa).

BARROSO, Luís Roberto. Constituição, Democracia e Supremacia Judicial: Direito e Política no Brasil Contemporâneo. Revista Jurídica da Presidência, v. 12, n. 96, p. 6-7, fev./mai. 2010.

BRASIL. Ministério da Administração Federal e Reforma do Estado. Plano Diretor da Reforma do Aparelho do Estado. Brasília, Imprensa Nacional, 1995.

Constituição (1988). Constituição da República Federativa do Brasil. Brasília, DF: Senado Federal, 1988. 292 p.

BRESSER PEREIRA, Luiz Carlos. A Reforma do Estado os anos 90: Lógica e Mecanismo de Controle. Brasília: Ministério da Administração Federal e Reforma do Estado, 1997. (Caderno MARE da Reforma do Estado; v. 1).

BRESSER PEREIRA, Luiz Carlos. Reflexões sobre a reforma gerencial brasileira de 1995, Revista do Serviço Público, v.50, n.4, 1999.

CENTRO LATINO-AMERICANO DE ADMINISTRAÇÃO PARA O DESENVOLVIMENTO/CLAD. Uma nova gestão pública para a América Latina. Revista do Serviço Público, Brasília, Ano 50, n. 1, jan./mar. 1998.

CNJ. CONSELHO NACIONAL DE JUSTIÇA. Estratégia do Poder Judiciário. Brasília, 2009.

Relatório Anual 2010. Brasília, 2011.

COSTA, Silvia Generali da; MARTINEWSKI, Cláudio Luís; VIEIRA, Luciano José Martins. Planejando a estrutura do judiciário para o futuro: a difícil busca por indicadores confiáveis. Revista da AJURIS, Porto Alegre, Ano XXXIII, n. 103, setembro, 2006, Doutrina Nacional, p. 305-322.

FADUL, Élvia; SILVA, Lindomar Pinto. Retomando o debate sobre a Reforma do Estado e a nova administração pública. In: XXXII EnANPAD, 2008, Rio de Janeiro. Anais... Rio de Janeiro: ANPAD, 2008.

FADUL, Élvia; SOUZA, Antônio Ricardo. Políticas de reformas da administração pública brasileira: uma compreensão a partir de seus mapas conceituais. In XXIX EnANPAD, 2005, Brasília. Anais. Rio de Janeiro, 2005.

FREIRE, Geovana Maria Cartaxo de Arruda; ROVER, Aires José. A Reforma do Judiciário: uma análise sistêmica da nova estrutura e organização. Revista Pensar, Fortaleza, n. 2, jul./dez. 2012, p. 476-498.

LIMA, Tatiana Cristina; CRUZ, Marcus Vinicius Gonçalves da. O Conselho Nacional de Justiça e as Reformas do Poder Judiciário: aspectos da Tecnologia da Informação.In: XXXV EnANPAD, 2011, Rio de Janeiro. Anais... Rio de Janeiro: ANPAD, 2011. 
MARINI, C. Gestão Pública: O debate contemporâneo. Cadernos da Fundação Luís Eduardo Magalhães, Salvador, n.7, 2003

MATIAS-PEREIRA, José. Administração pública comparada: uma avaliação das reformas administrativas no Brasil, EUA e União Européia. RAP. Rio de Janeiro. v. 42, n.1, p.61-82, jan./fev., 2008.

MODESTO, Paulo. Notas para um Debate sobre o Princípio Constitucional da Eficiência. Revista Eletrônica de Direito Administrativo Econômico (REDAE), Salvador, Instituto Brasileiro de Direito Público, n. 10, mai./jun./jul., 2007. Disponível na Internet: <http://www.direitodoestado.com.br>. Acesso em: 28 de junho de 2012.

MORAES, Germana de Oliveira; FREIRE, Geovana Maria Cartaxo de Arruda. O Conselho Nacional de Justiça como ponto de mutação do sistema judicial brasileiro. In: CONGRESSO NACIONAL DO CONPEDI, 20, 2011, Vitória. Anais... Vitória: CONPEDI, 2011. p. 1147-1171.

MOTTA, Paulo. Revendo estrategicamente as organizações do Poder Judiciário: uma perspectiva gerencial. Caderno FGV Projetos. Poder Judiciário e Gestão Eficiente. Ano 5, n. 12. mai./jun. 2010. Disponível em: <http:// fgvprojetos.fgv.br/sites/fgvprojetos.fgv.br/files/536.pdf> . Acesso em: 22.4.2013

PAULA, Maria Eunice de. Poder Judiciário: crise e reforma. 2006. 131f. Dissertação (Mestrado em Direito) - Programa de Pós-Graduação em Direito, Faculdade de Direito, Universidade Federal do Rio Grande do Sul, Porto Alegre, 2006.

RENAULT, Sérgio RabelloTamm. A Reforma do Poder Judiciário sob a ótica do Governo Federal. Revista do Serviço Público. Brasília 56 (2), abr./jun. 2005, p. 127-136.

RODOVALHO, Maria Fernanda de Toledo. A Reforma do Estado após a emenda constitucional 45/04: a reforma do poder judiciário.Tese de doutorado da Fundação Getúlio Vargas, 2012. Disponível em: <http://bibliotecadigital.fgv.br>. Acesso em: 7 de abril de 2013.

SADEK, Maria Tereza. Poder Judiciário: perspectivas de reforma. Revista Opinião Pública, Campinas, v. 10, n. 1, p. 1-62, mai. 2004.

SECCHI, Leonardo. Modelos organizacionais e reformas da administração pública. RAP. Rio de Janeiro 43(2): 347-69, mar./abr. 2009.

SENA, Gabriel Astoni. A Reforma do Poder Judiciário no Brasil: uma análise a partir das metas do Conselho Nacional de Justiça. In: XXXVI EnANPAD, 2012, Rio de Janeiro. Anais... Rio de Janeiro: ANPAD, 2012.

SENA, Gabriel Astoni; SILVA, Edson Arlindo; LUQUINI, Roberto de Almeida. A reforma do poder judiciário no Brasil: uma análise a partir do modelo gerencial. Revista de Ciências da Administração, v. 14, n. 33, agosto: 68-78, 2012. Universidade Federal de Santa Catarina, Florianópolis, Santa Catarina, Brasil. 
VIEIRA. Luciano José Martins; PINHEIRO, Ivan Antônio. Contribuições do Conselho Nacional de Justiça para a Gestão do Poder Judiciário. . In: XXXII EnANPAD, 2008, Rio de Janeiro. Anais... Rio de Janeiro: ANPAD, 2008.

\section{Notas}

${ }^{1}$ Doutoranda em Engenharia de Produção na Universidade Federal de Santa Catarina/UFSC. Mestrado em Administração na Universidade Salvador Unifacs, Laureate International Universities. Especialização em Direito Administrativo na Unibrasil e no Instituto de Direito Romeu Felipe Bacellar. Graduação em Administração na Universidade Federal de Santa Catarina/ UFSC e em Direito pela Universidade Vale do Itajaí/Univali.

${ }^{2}$ A EC n. 19/1998 incluiu no rol de princípios que regem a Administração Pública o princípio da eficiência (art. 37, caput).

Sobre o assunto, cabe trazer o entendimento excerto do artigo de Paulo Modesto apud Juarez Freitas (2007), in litteris: "Eficiência, para fins jurídicos, não é apenas o razoável ou correto aproveitamento dos recursos e meios disponíveis em função dos fins prestados, como é corrente entre os economistas e os administradores. A eficiência, para os administradores, é um simples problema de otimização de meios; para o jurista, diz respeito tanto à otimização dos meios quanto a qualidade do agir final. Recorde-se que o administrador público é obrigado a agir tendo como parâmetro o melhor resultado, consultando-se o princípio da proporcionalidade."

${ }^{3}$ Nesse caso, poderíamos citar a Santa Casa de Misericórdia de São Paulo. ${ }^{4}$ Publicização: processo de transformar uma organização estatal em uma organização de direito privado, mas pública não estatal (BRESSER PEREIRA, 1997a, p.18).

Sobre este último aspecto, inclua-se a accountability, que, segundo Secchi (2009, p. 354) "[...] é um termo de difícil tradução para o português. Literalmente accountability significa a prestação de contas por parte de quem foi incumbido de uma tarefa àquele que solicitou a tarefa (relação entre o agente e o principal). Aaccountability pode ser considerada o somatório dos conceitos de responsabilização, transparência e controle. Para Bresser Pereira (1997a), esse termo se refere a mecanismos de responsabilização ou de controle responsabilização por resultados, competição administrada por excelência, responsabilização social e na auditoria de resultados.".

"Judicialização, no entender de Luís Roberto Barroso (2010), significa "[...] que questões relevantes do ponto de vista político, social ou moral estão sendo decididas, em caráter final, pelo Poder Judiciário. Trata-se, como intuitivo, de uma transferência de poder para as instituições judiciais, em detrimento das instâncias políticas tradicionais, que são o Legislativo e o Judiciário".

'Conforme explica Sadek (2004), no desenho constitucional aprovado em 1988 algumas características devem ser salientadas: todos os princípios 
democráticos básicos que sustentam a fundação de um Estado governado pela Lei foram garantidos; direitos e garantias fundamentais foram ampliados de modo a incluir um amplo espectro de direitos supraindividuais, tais como direitos difusos e coletivos, e foram criados instrumentos necessários para a defesa desses direitos; a preocupação com a desigualdade social e econômica provocou a inclusão não só de preceitos de igualdade jurídica, mas de medidas afirmativas para diminuir ou solucionar esses problemas; foi ampliada a lista de artigos que não podem ser modificados, nem mesmo por emenda constitucional (cláusulas pétreas); houve ambiguidade em relação ao tipo de governo - por um lado, afirmação do sistema presidencialista e, por outro, criação de instrumentos típicos do sistema parlamentarista, como as medidas provisórias. O tipo de sistema presidencialista escolhido adotou o princípio da separação e independência entre os poderes; tal modelo, contudo, estimula mais o conflito entre os diferentes ramos do que a cooperação. Isto porque, ao mesmo tempo em que fortaleceu o Legislativo, ampliando sua capacidade de fiscalizar e controlar o Executivo, facultou ao Executivo a possibilidade de legislar por meio de medidas provisórias. Essas potencialidades aumentaram a responsabilidade do Judiciário de exercer a mediação política entre os dois outros poderes e no controle constitucional dos atos legislativos e de governo.

${ }^{8}$ Constituição Federal/88, art. 50, inciso, LXXIV - o Estado prestará assistência jurídica integral e gratuita aos que comprovarem insuficiência de recursos; art.134 - A Defensoria Pública é instituição essencial à função jurisdicional do Estado, incumbindo-Ihe a orientação jurídica e a defesa, em todos os graus, dos necessitados, na forma do art. $5^{\circ}$, LXXIV.

${ }^{9}$ O mapa está disponível na internet, no site www.ipea.gov.br/mapadefensoria.

${ }^{10} \mathrm{~A}$ súmula de efeito vinculante (state decisis) garante a segurança jurídica e evita à multiplicação, considerada desnecessária, de processos nas várias instâncias; obriga os juízes de primeira instância a cumprir as decisões dos tribunais superiores, mesmo discordando destas, impedindo assim, que grande parte dos processos tivesse continuidade, desafogando o Judiciário de processos repetitivos (SADEK, 2004, p. 28). Art. 102, § $2^{\circ}, \mathrm{CF} / 88$.

${ }^{11}$ Ferramenta que possibilita ao Supremo Tribunal Federal selecione os Recursos Extraordinários que irá analisar de acordo com os critérios de relevância jurídica, política, social ou econômica; este filtro resulta numa diminuição do número de processos encaminhados à Suprema Corte. Uma vez constatada a existência de repercussão geral, o STF analisa o mérito da questão e a decisão proveniente dessa análise será aplicada posteriormente pelas instâncias inferiores, em casos idênticos. Art. 102, § 3º, CF/88. Disponível em: <www.stf.jus.br/portal/glossario/ververbete.asp.> Acesso em 13.5.2013.

${ }^{12}$ Art. 5 , LXXVIII, Constituição Federal de 1988: "[...] a todos, no âmbito judicial e administrativo, são assegurados a razoável duração do processo e os 
meios que garantam celeridade de sua tramitação". (Incluído pela Emenda Constitucional n. 45, de 2004).

${ }^{13}$ O Justiça em Números é um banco de dados construído por meio de dados disponibilizados pelos tribunais brasileiros, que permite a avaliação dos tribunais em relação à quantidade de processos, questão financeira e o acesso à Justiça; analisa ainda o perfil de cada região e Estado, com base nas informações sobre população e economia. Vale salientar que somente a partir do ano de 2010 foram estabelecidas metas para a Justiça Eleitoral. (CNJ, 2011).

${ }^{14}$ Pesquisas: USP, 1994, IDESP, Sadia e Arantes (1995) "A crise do Judiciário e a visão dos juízes"; Escola de Direito de São Paulo - Fundação Getúlio Vargas (ICJ - Brasil 2010) - percepção da população em relação ao Judiciário; BRASIL-IPEA, 2011; Moraes e Freire, 2011).

${ }^{15} \mathrm{Em}$ determinadas situações, especialmente nas ações coletivas, não é possível alcançar o objetivo da justiça sem o sacrifício do quesito eficiência, notadamente no que concerne ao tempo de tramitação do processo. Por outro lado, demandas repetitivas, a respeito das quais há decisões já consolidadas na Jurisprudência, não podem ter um julgamento lento. $O$ andamento de todas as demandas é aferido pelo mesmo critério de planilha, o que faz com que a rapidez da resposta pareça preponderar sobre o critério justiça. (RODOVALHO, 2012, p. 116).

${ }^{16}$ Nesse sentido, Abrucio (2004), ao analisar as reformas no mundo, constata que estas apresentam um viés incremental: em vez de uma concepção totalizadora de reforma, que supõe a necessidade de uma alteração completa do status quo e a um só tempo, a concepção incrementalista reconhece que mudanças importantes se dão gradualmente, e que cada medida tomada e/ ou aprovada influencia, em maior ou menor medida, o caminho posterior - é a chamada pathdependence, ou histerese, para adequar o sentido original a uma palavra em português. Ocorre algo como uma sedimentação por "camadas geológicas". Nessa mesma linha, Gerald Caiden constatou que as reformas administrativas pelo mundo afora foram realizadas menos por esquemas grandiosos de transformação e mais por aperfeiçoamento e melhorias substantivas incrementais (CAIDEN, 1991, p.87). A ênfase no caráter incremental das reformas não só leva em conta a sua recorrência empírica, como o estudo de Caiden constata para a área administrativa, mas também pressupõe que esse modelo possa conjugar melhor os ângulos do desempenho e da democratização das políticas. O incrementalismo pode ser visto como uma contraposição analítica e normativa em relação à visão totalizadora de mudança, fundada numa concepção tecnocrática e insulada de reforma. Ao contrário do que supõe essa concepção, a prática incrementalista, ao incluir mais atores e estender no tempo o processo de transformação, não reduz necessariamente a coerência e a consistência dos 
projetos. Na verdade, ao abrir mais espaços de discussão e fazer as alterações aos poucos, pode-se aprender mais com os possíveis erros de implementação (variável do desempenho) e tornar as decisões mais responsivas e responsáveis (variável democrática) (ABRUCIO, 2004). 